\title{
Research on the Reform Methods of College Music Teaching under the New Media
}

\author{
Wang Xiuli \\ Silk Road Art College, Weinan Teachers University, Weinan, Shaanxi, 714000
}

Keywords: New Media; College Music Teaching; Reform

Abstract: The development of computer and network technology is pushing the new media technology forward. New media technology has a far-reaching impact on our work and learning. The college music course is a very practical course, but the traditional college music teaching has largely ignored this fundamental attribute of music. The popularity of New media technology has brought tremendous opportunities for the innovation of college music teaching methods. How to make full use of new media technology and realize the reform and innovation of college music teaching methods is a realistic problem that needs to be solved in front of every college music educator.

\section{Introduction}

Music is a practical and highly applied subject. With the continuous development of the economy and society, the demand for professional music talents in China has shown an increasing trend year by year. However, there are still great contradictions between the talent cultivation ability and quality in Chinese universities and the needs of economic and social development. After years of development, music teaching in colleges and universities in China has made great achievements in many aspects, which is obvious to all. However, we cannot turn a blind eye to the problems in the teaching of college music. On the contrary, we should be more aware of the shortcomings in education and teaching. Only in this way can we improve the level of music teaching in colleges and universities, and further optimize the training and output mechanism of talents in China.

New media is a collective term, and new media is both an environment and a technology. New media is the product of highly developed network and information technology. New media technology has unwittingly affected our lives in many areas. New media technology can transform dull and boring information into flexible and vivid multimedia, allowing people who come into contact with this information to make a qualitative leap in both sensory and cognitive.

The continuous maturity and wide application of new media technology has provided many channels for the innovation of college music teaching methods. How to perfectly combine new media technology with college music teaching, subverting the traditional education teaching mode has become an important support and breakthrough in the reform of college music teaching in the new era. 


\section{The Shortcomings in the Current College Music Teaching}

The disadvantages of traditional music teaching mainly exist in the aspects of education and teaching mechanism, methods of education and teaching, setting of education and teaching content, and evaluation system of education and teaching. The traditional college music teaching regards the classroom as the main position of education and teaching, and the teaching process has basically no extension. Under this educational and teaching mechanism, the classroom has basically become the only position for students to acquire knowledge. In the classroom teaching, the teacher is in a dominant position, and one-way knowledge transfer between teachers and students is the most important form of education and teaching. Although over the years, with the application of slides, multimedia and other technologies, the content of classroom teaching has been rich and improved. However, the traditional routines still follow the whole process. It is difficult for teachers and students to achieve timely information exchange in classroom teaching and many students will leave the problem after class. Because the class time is limited, the teacher must not only pay attention to the progress of the teaching, but also make certain questions and answers to the students. The contradiction between teaching and learning is more prominent. In the teaching content, due to the limitations of teaching time and conditions, many teachers can not explain the knowledge points or related cultural connotations. Students can only follow the teacher's thinking completely in teaching. When they encounter content or knowledge that they are interested in, they can't expand effectively, which greatly discourages students' interest and enthusiasm in learning. One of the reasons why traditional college music teaching pays more attention to the teaching of theoretical knowledge is that the assessment of theoretical knowledge can be uniform and easy to operate, and the assessment mechanism is relatively easy to establish and follow. In contrast, the assessment of practical ability is much more complicated. The assessment of practical ability requires complex standards and a more scientific system. Although many colleges and universities have made certain attempts and efforts, they have had little effect. This is closely related to the background of the original exam-oriented education, and it is inseparable from the corresponding technical conditions and means.

\section{Analysis of Characteristics of New Media Technology}

We must do a good job in reforming the method of college music teaching in the new media era. First of all, we should have some understanding of the many characteristics of new media technology. The new media technology has broken through the limitations of traditional media technology in terms of information dissemination and performance. The new media technology has a novel form and a clear image. The new media technology integrates many elements such as sound, video and text, and displays them through different expressions. The information displayed by the new media technology is flexible, diverse and lively. Secondly, the means of storing information under the new media has been greatly strengthened. New media technology can be integrated with massive storage information, and information acquisition and search can be carried out efficiently and conveniently. Finally, new media technology is very interactive. Under the new media technology, information can realize real-time communication and interaction between the two parties rather than just a passive display. Introducing new media technology into college music teaching can effectively improve the fun of college music teaching. The majority of teachers can break through the limitations of time and space, change the rigid impression of traditional teaching, and turn the boring knowledge into a vivid teaching demonstration. The many characteristics of new media technology can strengthen the flexibility of college music teaching, and even change the technical bottleneck of traditional evaluation methods, so that college music teaching will go to a new stage of development. 


\section{Innovation of College Music Teaching Methods in the New Media Era}

In the new media era, we should focus on the following aspects in order to do a good job in the innovation of college music teaching methods.

\subsection{Change the Traditional Concept of Education and Teaching}

The reason why the change of the concept is in the first place is that there has been a certain gap in the teaching philosophy of our college music education compared with foreign counterparts. Although new media technology has many advantages, they ultimately require human to control and design. Therefore, if we do not change the deep-seated ideas, it is difficult to integrate this technology with the needs of education and teaching. We must change the traditional education and teaching ideas, keep up with the pace of the times, be good at innovation, and apply various advanced educational concepts and education and teaching ideas to the reform of college music teaching. Besides, we should also use advanced education and teaching concepts to guide the innovation of college music teaching methods. In recent years, many scholars and educators have made effective explorations and attempts in how to change the traditional education and teaching concepts from theory and practice, and achieved good results.

\subsection{Break Regular Teaching Mode with New Media Technology}

In the traditional teaching mode, teachers are the masters of the classroom, and they impart knowledge and information to students in a limited time. Teachers teach content inflexibly, and students are more passively accepted. Although this mode is widely criticized, it has been used. The teaching of this mode make students gradually lose their autonomy and unable to effectively improve their comprehensive ability and quality. New media technology has effectively extended teaching in time and space. In recent years, micro-courses have developed into an important auxiliary means for college music teaching under the new media technology. The micro-course is a small course designed for a certain teaching content. It often uses video as the main carrier. The micro-course records the wonderful teaching process that the teacher conducts around a certain knowledge point inside and outside the classroom. The duration of micro-courses is generally short, often within ten minutes. This is indeed a bit short compared to the 45-minute period of traditional class, but the micro-courses are not small, and micro-courses play an extremely important role in new media teaching. With the popularization of network technology, especially the construction of campus network, the network is no longer a bottleneck restricting the communication between teachers and students. The popularity of the campus network provides a good environment for the dissemination of micro-courses. The development and utilization of micro-courses allows students to collect and learn course-related knowledge and information anytime and anywhere in the computer and mobile client, which has become the core of college education reform. The introduction of micro-course fully mobilized the enthusiasm and initiative of students. It changes the teacher-led teaching mode to the student-independent learning mode. Students can find insufficiency in the learning of micro-courses, sum up and improve, and even many students participate in the production of micro-courses. Through self-learning and independent thinking, students not only strengthen their theoretical knowledge, but also exercise their practical ability. Foreign studies have shown that the effective learning time of students in the classroom is often concentrated in the first twenty minutes of the course, after which students' attention will reduce to varying degrees regardless of the effect or the attention of learning. The popularity of micro-courses fully compensates for the weaknesses of classroom teaching and overcomes the constraints of classroom teaching. In recent years, there have been a few cases in which the introduction of 
flipping classroom to college music teaching and it has achieved good teaching results. Flipping classroom is another successful case of combining new media with college music teaching. There are similarities and differences between flipping classroom and micro-course. The design of the flipping classroom is also student-centered, using multimedia and other information technology to drive the initiative and consciousness of students. Flipping classroom also fully considers the different levels of learning of students. In the process of learning, through the interaction of teachers and students, interaction between students, and learning group collaboration, the roles that need to be undertaken by the majority of music teachers in the traditional classroom are distributed to students, and the initiative of learning is completely given to students. Since 2012, the practice and application of flipping classroom have been deepened, and the teaching results obtained by them have been fully affirmed by the Ministry of Education. The Ministry of Education of China has listed the integration and development of information technology and education in the ten-year development plan as the direction and focus of education and teaching reform.

\subsection{Integrate Educational and Teaching Resources with New Media Technology}

New media technology relies on network and information technology to realize long-distance transmission and resource sharing of information. Relying on the new media technology, college music teaching should fully integrate the educational and teaching resources. The majority of teachers should fully explore and organize all kinds of educational and teaching resources. At the same time, resources should be updated regularly, and should not be static. The majority of teachers should fully encourage students to participate in the integration of music education and teaching resources, so that students can find the learning materials that they are interested in and make multimedia resources that help them to learn, which can fully tap the potential of students in the interaction between teaching and learning.

\subsection{Use New Media Technology to Create a New Music Learning Environment}

The application of new media technology has made it possible to create a new music learning environment. How to create a good music learning environment plays an important role in improving the music learning ability of college students. In the regular music class, due to limitations of time and conditions, the teacher can not present some background knowledge of the music, writers and other information. There is not much time for students to practice their skills, which has caused many students to have high scores and low ability. New media technology can create a good learning environment for students through the use of technical means. Sound and images are the two most widely used methods of information transfer in new media technology. In addition, network resources such as music library, distance education system, and campus network classroom under the new media can provide students with a very excellent music learning environment.

\section{Conclusion}

With the progress of society and the changes of the times, our requirements for talent training goals are getting higher and higher. As an important part of the university's basic curriculum, the university music curriculum plays an important role in the entire higher talent cultivation system. The traditional college music teaching mode can no longer meet the demands of social development and progress for talents. How to improve students' comprehensive application ability, and let students truly transform what they have learned into what they use is a major issue that we need to solve in education and teaching. The advent of the new media era provides a very broad platform 
for college music teaching innovation. Besides, the new media continues to enrich and influence the fields of our work, study and life at an unpredictable speed. As a music educator in colleges and universities, how to seize the opportunities brought by new media, give full play to its role in college music teaching, and effectively promote the sustainable development of college music teaching work becomes increasingly urgent and important.

\section{References}

[1] Liao Honggang. Research on the Curriculum of Musicology (Music Education Major) in Colleges and Universities [D]. Tibet University, 2017.

[2] Li Yang. Investigation and Analysis of Music Education in Colleges and Universities [D]. Xi'an Conservatory of Music, 2017.

[3] Liu Xianbo. Analysis of the Inheritance of Multi-Music Education and National Music Culture in Colleges and Universities [J]. Contemporary Music, 2017, (01): 23-24.

[4] Fan Xiaorong and Wang Liqian. The Significance and Content Reform of Music Education in Comprehensive Universities [J]. Education Theory and Practice, 2017, 37 (06): 54-56.

[5] Li Wenhong. Analysis of the Artistic Characteristics of Music Education in Colleges and Universities--A Case Study of Quality Education [J]. Heilongjiang Higher Education Research, 2017, (01): 171-173.

[6] Wang Jiaqi. Research on the Reform and Development Countermeasures of College Music Education in China [J]. Drama House, 2017, (03): 195-196.

[7] Chen Pu. Problems and Countermeasures of the Connection between Music Education Major and Basic Music Education in Colleges and Universities [J]. Shanghai Education Research, 2017, (01): 71-72.

[8] Wei Min. Research on Music Education in Higher Vocational Colleges from the Perspective of Quality Education [J]. Health Vocational Education, 2017, 35 (10): 19-20. 